\title{
PD 116,152, A NOVEL PHENAZINE ANTITUMOR ANTIBIOTIC DISCOVERY, FERMENTATION, CULTURE CHARACTERIZATION AND BIOLOGICAL ACTIVITY
}

\author{
J. B. Tunac, S. W. Mamber, B. D. Graham and W. E. Dobson \\ Warner-Lambert/Parke-Davis, Pharmaceutical Research, \\ Ann Arbor, MI 48105, U.S.A.
}

(Received for publication October 9, 1985)

\begin{abstract}
A novel phenazine antitumor antibiotic is described, produced by Streptomyces lomondensis subsp. galanosa NRRL 15738. The antibiotic is selectively active versus the bacterium Streptococcus pneumoniae (MIC $<0.46 \mu \mathrm{g} / \mathrm{ml}$ ); the antitumor activity versus murine P388 leukemia is $\mathrm{T} / \mathrm{C} 149$.
\end{abstract}

A novel phenazine type compound, PD 116,152 ${ }^{1}$ (Fig. 1) was discovered in the course of our screening program for antitumor antibiotics. The screening system involved a microorganism particularly sensitive to DNA-active compounds.

The producing organism has been identified as a new Streptomyces. The phenazine antibiotic was found to resemble lomofungin. ${ }^{2)}$ This paper describes the screening method, taxonomy of the producing-organism, fermentation and biological properties of the compound.

\section{Materials and Methods}

\section{Screening System}

A mutant organism Escherichia coli CM871, ${ }^{3)}$ characterized by 3-gene deletions (uvrA, recA, and $l e x A$ ) was obtained from the University of Auckland, New Zealand (c/o Dr. L. Ferguson). A slow-growing variant of this organism was subsequently isolated, designated as $E$. coli CM871NZ, and was used as the assay organism. A wild type strain, WP2NZ, was used as a control.

The screening system was carried out as a

Fig. 1. PD 116,152.<smiles>CC(=O)c1ccc(O)c2nc3c(O)c(C)c(O)c(C=O)c3nc12</smiles>

disk test. Thus, the fermentation samples were

disked on a plate seeded with the test organism. For control, an agar plate seeded with the wild type strain, E. coli WP2NZ was disked with the same fermentation samples.

The agar plating medium included an agar base layer and a soft-agar overlay. The base agar consisted of $\mathrm{K}_{2} \mathrm{HPO}_{4} 0.7 \%, \mathrm{KH}_{2} \mathrm{PO}_{4} 0.3 \%$, sodium citrate $0.094 \%, \mathrm{MgSO}_{4} \cdot 7 \mathrm{H}_{2} \mathrm{O} 0.01 \%,\left(\mathrm{NH}_{4}\right)_{2} \mathrm{SO}_{4}$ $0.1 \%$, dextrose $2 \%$, casein hydrolysate $5 \%$, L-tryptophan $0.2 \%$ and agar $1.5 \%$. The pH was adjusted to 7.3 before autoclaving. Glucose, casein hydrolysate and L-tryptophan were sterilized separately. The soft-agar overlay consisted of agar $1.0 \%$.

The assay plate was prepared by pouring $30 \mathrm{ml}$ of the molten base agar onto a $150 \times 25 \mathrm{~mm}$ (LabTek) Petri plate; after it was solidified, $10 \mathrm{ml}$ of the soft-agar seeded with the organism were evenly overlayed. Paper disks $(12.7 \mathrm{~mm})$ dipped in the fermentation beers were laid onto the plate and the plate was incubated overnight at $37^{\circ} \mathrm{C}$. Fermentation samples considered positive in the test showed inhibition zones versus $E$. coli CM871NZ at least $4 \mathrm{~mm}$ larger than the zones in the control E. coli WP2NZ. 


\section{Culture Characterization}

The culture was isolated from a soil collected in St. Thomas, Virgin Islands. The soil was plated on a modified Lindenbein medium. ${ }^{4}$ )

Culture characterization was carried out following the ISP procedure. ${ }^{5)}$ In addition CIM-23 medium $^{\text {() }}$ was used. Cell wall and whole cell analyses were carried out following the procedure of BECKer et al..$^{7)}$ and LeCHeVAlier, ${ }^{8)}$ respectively.

Fermentation

Stock cultures of the organism were maintained in lyophilized vials, and working cultures stored as cryovials in liquid nitrogen refrigerator (Union Carbide, Indianapolis). To start a fermentation, the contents of a thawed cryovial was used to inoculate a $300-\mathrm{ml}$ seed flask (Bellco, Shallow baffle) containing $50 \mathrm{ml}$ of seed medium. The seed medium consisted of $0.5 \%$ yeast hydrolysate (Amberex 1003 , Amber Labs.), Cerelose $0.1 \%$, dextrin (Amidex B411, Corn Products) $2.4 \%$, hydrolyzed peptone (N-Z case, Humko-Sheffield) $0.5 \%$, spray-dried meat solubles (Daylin Labs.) $0.3 \%$ and $\mathrm{CaCO}_{3} 0.2 \%$.

The production of the antibiotic was carried out in 300-ml shake-flasks, 30-liter stirred-jars, or in 760-liter fermentors. The production medium consisted of maltose (Eastern Chem.) $2.5 \%$, distillers solubles (Grain Processing) $0.5 \%$, safflower meal (PVO International) $0.75 \%$, torula yeast (Rhinelander Paper Co.) $0.2 \%, \mathrm{NaCl} 0.1 \%$ and $\mathrm{CaCO}_{3} 0.25 \%$. The fermentation conditions were as follows: shakeflask, $50 \mathrm{ml} / 300-\mathrm{ml}$ flask, $200 \mathrm{rpm}$ shaker speed (Model G-53 New Brunswick Co.); 30-liter stirredjar, 16 liters/jar $1 \mathrm{vol} / \mathrm{vol} / \mathrm{minute}$ air, $300 \mathrm{rpm}$; and 760-liter fermentor, 600 liters/tank, $0.75 \mathrm{vol} / \mathrm{vol} /$ minute air, $155 \mathrm{rpm}$. The fermentations were carried out for 72 hours at $33^{\circ} \mathrm{C}$.

Assay and Antitumor Activity

The antibiotic was assayed by both inhibition zone versus $E$. coli $\mathrm{CM} 871 \mathrm{NZ}$ and by high pressure liquid chromatography (HPLC). The HPLC assay method involved a 4.1 (ID) $\times 250 \mathrm{~mm}$ PRP-1 column (Hamilton Co., Reno) and a mobile phase consisting of a linear gradient form of $0.025 \mathrm{M}, \mathrm{pH}$ 9.5 , borate buffer - acetonitrile - methanol $(90: 5: 5)$ at time zero, to $0.025 \mathrm{M}, \mathrm{pH} 9.5$, borate buffer acetonitrile - methanol $(70: 25: 5)$ over a course of seven minutes at a flow rate of $2.0 \mathrm{ml} / \mathrm{minute}$. The retention time of the antibiotics in this system was 3.5 minutes.

The in vivo antitumor activity was evaluated versus P388 murine lymphocytic leukemia tumor cell line in CDF, mice..$^{9)}$ The tumor cells were injected intraperitoneally (ip) on day 0 , and the antibiotic was administered ip on day 1 through 9.

\section{Antimicrobial Activity}

The antimicrobial activity of the compound was evaluated by the broth dilution method. ${ }^{10)}$ Because of the poor water solubility, the antibiotic was dissolved in methanol then diluted with distilled water to bring the final solvent concentration to $10 \%$. Subsequent dilutions were made in the media previously dispensed in the microdilution trays.

\section{Results}

\section{Morphological and Cultural Characteristics}

Whole cell and cell wall analyses revealed LL-2,6-diaminopimelic acid (L-DAP) and glycine with no characteristic sugars. The organism produced aerial and substrate mycelia typical of Streptomyces.

The growth characteristics of the organism on different media is shown on Table 1, carbon utilization on Table 2, and physiological properties on Table 3. In reviewing the literature, some of these characteristics resembled Streptomyces lomondensis NRRL 3252.11) For this reason side-by-side comparative studies were carried out for the two organisms. Some notable differences include spore chain morphology, spore wall ornamentation (Fig. 2), nitrate reduction, and production of soluble pigments (Table 4).

\section{Fermentation}

The fermentation pattern of the organism in a 756-liter fermentor is shown in Table 5. The pro- 
Table 1. Growth characteristics of Streptomyces lomondensis subsp. galanosa NRRL 15738.

\begin{tabular}{llllll}
\hline \multicolumn{1}{c}{ Medium } & $\begin{array}{c}\text { Aerial } \\
\text { growth }^{\mathrm{a}}\end{array}$ & $\begin{array}{c}\text { Mycelium } \\
\text { color }\end{array}$ & $\begin{array}{c}\text { Substrate } \\
\text { growth }\end{array}$
\end{tabular}

a +++ Good, ++ moderate, + poor.

Table 2. Carbohydrate utilization of strain WP4611 Streptomyces lomondensis subsp. galanosa NRRL 15738.

\begin{tabular}{lc}
\hline \multicolumn{1}{c}{ Test } & Results \\
\hline L-Arabinose & + \\
D-Fructose & + \\
D-Galactose & + \\
D-Glucose & + \\
$i$-Inositol & + \\
Inulin & + \\
Maltose & + \\
D-Mannitol & + \\
Melibiose & + \\
Raffinose & + \\
Rhamnose & + \\
Salicin & - \\
Sucrose & + \\
D-Xylose & + \\
\hline
\end{tabular}

+ Growth, - no growth.
Table 3. Physiological properties of Streptomyces lomondensis subsp. galanosa NRRL 15738.

\begin{tabular}{ll}
\hline Growth after & \\
$\quad 7$ days incubation: & $-\mathrm{a}$ \\
$11^{\circ} \mathrm{C}$ & +++ \\
$24^{\circ} \mathrm{C}$ & +++ \\
$28^{\circ} \mathrm{C}$ & ++ \\
$33^{\circ} \mathrm{C}$ & +++ \\
$37^{\circ} \mathrm{C}$ & - \\
$45^{\circ} \mathrm{C}$ & Positive in 48 hours \\
Nitrate reduction: & Positive in 6 days- \\
Gelatin liquefaction: & brown pigment \\
& Negative ater 21 days \\
Skim milk peptonization: & Positive \\
Production of: & Positive \\
$\mathrm{H}_{2} \mathrm{~S}$ & Positive \\
Melanin & + poor, - no growth.
\end{tabular}

Fig. 2. Electron micrographs of spores of Streptomyces lomondensis subsp. galanosa NRRL 15738 (A) showing warty ornamentation compared to the spiny spores of S. lomondensis NRRL 3252 (B) $(\times 46,100)$.

(A)

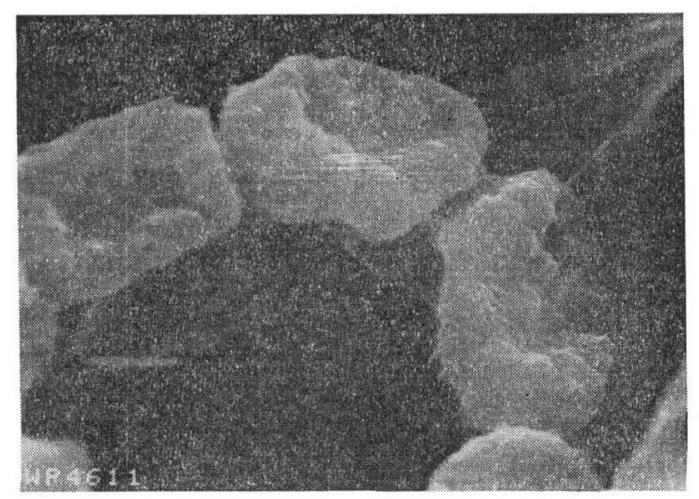

(B)

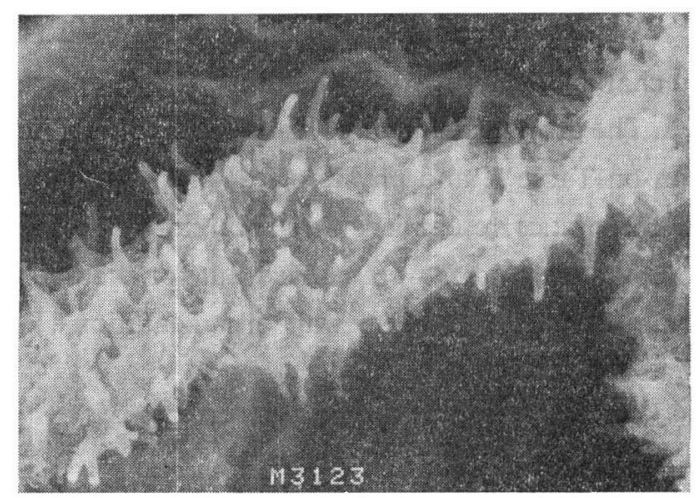


Table 4. Side-by-side comparison of Streptomyces lomondensis subsp. galanosa NRRL 15738.

\begin{tabular}{|c|c|c|c|}
\hline \multirow{2}{*}{\multicolumn{2}{|c|}{ Property }} & \multicolumn{2}{|c|}{ Cultural description } \\
\hline & & WP4611 & M3123 \\
\hline \multirow{2}{*}{\multicolumn{2}{|c|}{$\begin{array}{l}\text { Whole cell analysis } \\
\text { Spore chain morphology }\end{array}$}} & L-DAP; no characteristic sugar & L-DAP; no characteristic sugar \\
\hline & & $\begin{array}{l}\text { Long tight spirals few open } \\
\text { spirals rare straight chains }\end{array}$ & $\begin{array}{l}\text { Mostly straight and open spirals } \\
\text { few tighter spirals - shorter than } \\
\text { WP4611. }\end{array}$ \\
\hline \multicolumn{2}{|c|}{ Spore wall ornamentation } & Rough to warty & Spiny \\
\hline \multirow{3}{*}{$\begin{array}{l}\text { Diffusable pigments: } \\
\text { (melanin formation) }\end{array}$} & ISP-1 & Brown & None \\
\hline & ISP-6 & Black & Black \\
\hline & ISP-7 & Brown & Brown \\
\hline \multicolumn{2}{|l|}{ Gelatin liquefaction } & Positive-brown & Positive-brown \\
\hline \multicolumn{2}{|l|}{ Nitrate reduction } & Positive & Negative \\
\hline \multicolumn{2}{|l|}{ Culture growth } & No growth at 11 and $42^{\circ} \mathrm{C}$ & No growth at 11 and $42^{\circ} \mathrm{C}$ \\
\hline \multicolumn{2}{|l|}{ Milk coagulation } & Negative & Negative \\
\hline \multirow{2}{*}{\multicolumn{2}{|c|}{ Milk peptonization }} & Negative & Negative \\
\hline & & (brown pigment) & (light brown pigment) \\
\hline \multirow[t]{5}{*}{ Aerial mycelia: } & ISP-2 & Aqua grey (19dc) & Aqua grey (19dc) \\
\hline & ISP-3 & Slight white & Slight white \\
\hline & ISP-4 & Aqua grey (19dc) & Aqua grey (19dc) \\
\hline & ISP-5 & Aqua grey (19dc) & Aqua grey (19dc) \\
\hline & CIM23 & Aqua grey (19dc) & Aqua grey (19dc) \\
\hline \multirow[t]{5}{*}{ Substratal mycelia: } & ISP-2 & Clove brown (3pl) & Brown mahogany (6pi) \\
\hline & ISP-3 & Butterscotch (3ne) & Maple (4ng) \\
\hline & ISP-4 & Coffee (3pn) & Dark brown (4pn) \\
\hline & ISP-5 & Orange rust $(4 \mathrm{pl})$ & Wine (7pg) \\
\hline & CIM23 & Clove brown $(3 \mathrm{pl})$ & Clove brown $(3 \mathrm{pl})$ \\
\hline
\end{tabular}

Table 5. Production of PD 116,152 in a 756-liter fermentor.

\begin{tabular}{cccc}
\hline \multirow{2}{*}{$\begin{array}{c}\text { Fermentation stage } \\
\text { (hours) }\end{array}$} & \multicolumn{2}{c}{ Inhibitory zone $(\mathrm{mm})^{*}$} & \\
\cline { 2 - 4 } & E. coli WP2NZ & E. coli CM871 NZ & - \\
24 & 17.5 & 24.5 & - \\
36 & 15.5 & 23.5 & - \\
48 & 15.5 & 22.5 & - \\
60 & 15.0 & 22.0 & 4.0 \\
72 & 0 & 21.0 & $\mathrm{~g} / \mathrm{ml})$ \\
\hline
\end{tabular}

* $\quad 12.7 \mathrm{~mm}$ disks.

duction of the antibiotic started at about the 24-hour stage. In this example the fermentation fluid was harvested at the 72-hour stage with a yield of $\sim 4 \mu \mathrm{g} / \mathrm{ml}$.

Antimicrobial and Antitumor Activities

The antibiotic was notably active versus Streptococcus pneumoniae (MIC $<0.46 \mu \mathrm{g} / \mathrm{ml}$ ) with marginal activity versus Branhamella catarrhalis, Micrococcus luteus and S. pyogenes (Table 6). The compound was inactive versus the fungi tested in this study.

The antitumor activity versus $\mathrm{P} 388$ murine lymphocytic leukemia in vivo, expressed as \% T/C was 149. Toxicity was observed at $20 \mathrm{mg} / \mathrm{kg}$ at the described dosing schedule.

\section{Discussion}

The initial fermentation beer was active versus the microbial screen but activity was not detected 
in the L1210 tissue culture screen. This indicates the feasibility and effectivity of a microbial system as a front line screen for antitumor compounds. A purified PD 116,152, however, showed cytotoxicity versus $\mathrm{L} 1210$ in tissue culture $\left(\mathrm{ID}_{50} 0.17\right.$ $\mu \mathrm{g} / \mathrm{ml}$ ) but still considerably less than CI-920 ${ }^{12)}$ $\left(\mathrm{ID}_{50} 0.073 \mu \mathrm{g} / \mathrm{ml}\right)$ or CI-940 ${ }^{13)}\left(\mathrm{ID}_{50} 0.12 \mathrm{ng} / \mathrm{ml}\right)$.

PD 116,152 showed a very narrow antimicrobial spectrum with excellent activity versus $S$. pneumoniae and marginal activity versus other microorganisms. Other phenazine type antibiotics, lomofungin ${ }^{2)}$ and 1,6-dihydroxy-2-chlorophenazine ${ }^{14)}$ have shown potent and broad antimicrobial activities. The main differences of the above antibiotics from PD 116,152 are certain side groups, indicating the amenability of the compound to structural modification and corresponding changes in biological activity.

Notable differences were obseved between the PD 116,152 and lomofungin-producing cultures, particularly the spore chain morphology, spore wall ornamentation, melanin formation, nitrate reduction and soluble pigment production. The above differences however, do not seem to be significant enough to warrant the assignment of a new species. Therefore, we regard the PD 116,152-producing organism as a new subspecies for which we propose the name Streptomyces lomondensis subsp. galanosa. The organism has been deposited with the Northern Research Laboratory (NRRL), Peoria, IL with the accession number NRRL 15738.

\section{Acknowledgment}

This work was supported in part by the National Cancer Institute (NCI), USA, contract N01-CM-07379. We thank Dr. J. FreNCH and his staff in the Chemistry section for providing us the structure of PD 116,152, and to the NCI for the P388 in vivo data.

\section{References}

1) Smitka, T. A.; R. H. Bunge, J. H. Wilton, G. C. Hokanson, J. C. French \& J. Clardy: PD 116,152, a new antitumor phenazine antibiotic. J. Antibiotics, in preparation.

2) Tipton, C. D. \& K. L. Rinehart: Lomofungin I. Degradative studies of a new phenazine antibiotic. J. Am. Chem. Soc. 92: 1425 1426, 1970

3) Tweats, D. J.; M. H. L. Green \& W. J. Muriel: A differential killing assay for mutagens and carcinogens based on an improved repair-deficient strain of Escherichia coli. Carcinogenesis 2: 189 194, 1981

4) Williams, S. T. \& T. Cross: Actinomycetes. Methods Microbiol. 4: 295 334, 1971

5) Shirling, E. B. \& D. Gottlieb: Methods for characterization of Streptomyces species. Int. J. Syst. Bacteriol. 16: 313 340, 1966

6) Hickey, R. J. \& H. D. TreSner: A cobalt-containing medium for the sporulation of Streptomyces species. J. Bacteriol. 64: 891 892, 1952

7) Becker, B.; M. P. Lechevalier \& H. A. Lechevalier: Chemical composition of cell wall preparations for strains of various form-genera of aerobic actinomycetes. Appl. Microbiol. 13: 236 243, 1965

8) Lechevalier, M. P.: Identification of aerobic actinomycetes of chemical importance. J. Lab. Clin. Med. 71: $934 \sim 944,1968$

9) Goldin, A. \& J. M. Venditi: The new NCI screen and its implications for clinical evaluation. Cancer Res. 70: $5 \sim 20,1980$

10) Washington, J. A. \& V. L. Sutter: Dilution susceptibility test: Agar and macro-broth dilution procedures. In Manual of Clinical Microbiology. Ed., E. H. Lenette, pp. 453 458, American Soc. Microbiol., Washington, D.C., 1980 
11) Bergy, M. E. \& L. E. Johnson (Upjohn Co.): Antibiotic lomondomycin and method of production. U.S. Patent 3,359,165, Dec. 19, 1967

12) Tunac, J. B.; B. D. Graham \& W. E. Dobson: Novel antitumor agents CI-920, PD 113,270 and PD 113,271. I. Taxonomy, fermentation and biological properties. J. Antibiotics 36: 1595 1600, 1983

13) Tunac, J. B.; B. D. Graham, W. E. Dobson \& M. D. Lenzini: Novel antitumor antibiotics. CI-940 (PD 114,720) and PD 114,721. Taxonomy, fermentation and biological activity. J. Antibiotics 38: 460 465,1985

14) Patel, M.; V. Hegde, A. C. Horan, V. P. Gullo, D. Loebenberg, J. A. Marquez, G. H. Miller, M. S. PUAR \& J. A. WAITz: A novel phenazine antifungal antibiotic, 1,6-dihydroxy-2-chlorophenazine. Fermentation, isolation, structure and biological properties. J. Antibiotics 37: 943 948, 1984 